\title{
Opposing Catecholamine Changes in the Bed Nucleus of the Stria Terminalis during Intracranial Self-Stimulation and its Extinction
}

\author{
Jinwoo Park ${ }^{1,2}$, Elizabeth S. Bucher ${ }^{1}$, Khristy Fontillas $^{1}$, Catarina Owesson-White ${ }^{1}$, \\ Jennifer L. Ariansen ${ }^{1}$, Regina M. Carelli ${ }^{3,4}$, and R. Mark Wightman ${ }^{1,4,}{ }^{*}$ \\ ${ }^{1}$ Department of Chemistry, University of North Carolina at Chapel Hill, Chapel Hill, North Carolina \\ 27599-3290, USA \\ ${ }^{3}$ Department of Psychology, University of North Carolina at Chapel Hill, Chapel Hill, North \\ Carolina 27599-3290, USA
}

${ }^{4}$ Neuroscience Center, University of North Carolina at Chapel Hill, Chapel Hill, North Carolina 27599-3290, USA

\section{Abstract}

Background-While studies suggest that both dopamine and norepinephrine neurotransmission support reinforcement learning, the role of dopamine has been emphasized. As a result, little is known about norepinephrine signaling during reward learning and extinction. Both dopamine and norepinephrine projections innervate distinct regions of the bed nucleus of the stria terminalis (BNST), a structure that mediates behavioral and autonomic responses to stress and anxiety. We investigated whether norepinephrine release in the ventral (v) BNST and dopamine release in the dorsolateral $(d I)$ BNST correlate with reward learning during intracranial self-stimulation (ICSS).

Methods-Using fast-scan cyclic voltammetry, norepinephrine concentration changes in the vBNST ( $\mathrm{n}=12$ animals) during ICSS were compared to dopamine changes in the $d$ BNNST $(\mathrm{n}=7$ animals) and nucleus accumbens (NAc) ( $\mathrm{n}=5$ animals). Electrical stimulation was in the ventral tegmental area/substantia nigra region.

Results-Whereas dopamine release was evoked by presentation of a cue predicting reward availability in both $d \mathrm{BNST}$ and NAc, cue-evoked norepinephrine release did not occur in the vBNST. Release of both catecholamines was evoked by the electrical stimulation. Extracellular changes in norepinephrine were also studied during extinction of ICSS and compared to results obtained for dopamine. During extinction of ICSS norepinephrine release in the $v$ BNST occurred at the time where the stimulation was anticipated whereas dopamine release transiently decreased.

Conclusions-The data demonstrate that norepinephrine release in the $v$ BNST differs from dopamine release in the dIBNST and the NAc in that it signals the absence of reward rather than responding to reward predictive cues.

(C) 2012 Society of Biological Psychiatry. Published by Elsevier Inc. All rights reserved.

*Corresponding author: R. Mark Wightman, Ph.D., Department of Chemistry, CB \# 3290, Venable Hall, University of North Carolina at Chapel Hill, Chapel Hill, NC, 27599-3290, USA, Tel : +1 (919) 962-1472, Fax : +1 (919) 962-2388, rmw@ unc.edu.

${ }^{2}$ Present address: Department of Biotechnical and Clinical Laboratory Sciences, University at Buffalo, Buffalo, NY 14214

Publisher's Disclaimer: This is a PDF file of an unedited manuscript that has been accepted for publication. As a service to our customers we are providing this early version of the manuscript. The manuscript will undergo copyediting, typesetting, and review of the resulting proof before it is published in its final citable form. Please note that during the production process errors may be discovered which could affect the content, and all legal disclaimers that apply to the journal pertain.

Financial disclosure. All authors report no biomedical financial interests or potential conflicts of interest. 


\section{Keywords}

Intracranial self-stimulation (ICSS); Norepinephrine; Dopamine; Ventral bed nucleus of the stria terminalis ( $(\mathrm{BNST})$; Fast-scan cyclic voltammetry (FSCV); Extinction

\section{Introduction}

Intracranial self-stimulation (ICSS) is an operant behavior in which animals are conditioned to press a lever to deliver an electrical stimulation to specific brain regions (1-3). Early research suggested that norepinephrine was a critical neurotransmitter involved in ICSS (reviewed in (4)). Anatomical sites that supported ICSS were found near norepinephrine processes (5), and radioactive norepinephrine and its metabolites were released during ICSS(6). However, subsequent research found evidence to the contrary (7-10), and supported a more important role for dopamine in ICSS reward (11). Norepinephrine has also been suggested to be involved in the extinction of reward based behaviors, although this role has also been disputed (12-14).

ICSS studies have shown that mesolimbic dopamine neurons projecting from the ventral tegmental area (VTA) are important in the neural circuitry mediating reward (15). Indeed, dopamine has been viewed as the primary neurotransmitter involved in the rewarding aspects of ICSS (3). Our previous studies demonstrated that reward learning can be investigated by quantifying dopamine changes in the nucleus accumbens (NAc) with carbon-fiber microelectrodes using fast-scan cyclic voltammetry (16). Transient surges of extracellular dopamine become time-locked to cues that predict ICSS reward and coincide with cues associated with cocaine or food reward $(17 ; 18)$. Since dopamine transients are a direct result of burst firing of dopaminergic neurons (19), these results concur with electrophysiological recordings that demonstrated that the firing rate of dopamine neurons encode for a reward prediction error $(20 ; 21)$.

In this work we measure the roles of dopamine and norepinephrine during ICSS in the bed nucleus of the stria terminalis (BNST) and compare them to dopamine responses in the NAc. The BNST is part of the extended amygdala and serves as a relay center between limbic brain regions and the hypothalamic paraventricular nucleus (22). The anterior portion of the BNST receives both dopaminergic and noradrenergic inputs, but they are differentially distributed (23). The ventral ( $v$ ) BNST has the highest noradrenergic innervation in the brain (24) but has little dopamine content $(25 ; 26)$. In contrast, the dorsolateral $(d I)$ BNST receives dopaminergic innervation from the VTA and periaqueductal gray but contains negligible norepinephrine (27-31). The research reported here provides three new insights into the role of catecholamines in ICSS. First, dopaminergic responses in the dBNST were found to resemble dopaminergic responses in the NAc. Second, unlike dopamine, norepinephrine in the $v$ BNST was not released in response to cues that predicted lever availability. Third, during extinction, norepinephrine release occurred at the time of the anticipated electrical stimulation whereas there was a suppression of extracellular dopamine.

\section{Materials and Methods}

\section{Animals}

Male Sprague-Dawley rats ( $\mathrm{n}=24$, Charles River, NC), aged 90-120 d and weighing 280-380 g, were used. They were individually housed in a controlled temperature environment with a 12:12 light:dark cycle. Food and water were available ad libitum. All procedures were approved by the Institutional Animal Care and Use Committee of the University of North Carolina. 


\section{Surgery}

Rats were anesthetized with ketamine hydrochloride $(100 \mathrm{mg} / \mathrm{kg})$ and xylazine hydrochloride $(20 \mathrm{mg} / \mathrm{kg})$ administered intraperitoneally and placed in a stereotaxic frame. A guide cannula (Bioanalytical Systems, West Lafayette, IL) was positioned above the dIBNST (anteroposterior (AP) $-0.1 \mathrm{~mm}$, mediolateral (ML) $+1.6 \mathrm{~mm}$ ), the $v \mathrm{BNST}$ (AP 0.0 $\mathrm{mm}, \mathrm{ML}+1.2 \mathrm{~mm}$ ), or the NAc (AP $1.7 \mathrm{~mm}$, ML $0.8 \mathrm{~mm}$ ). Coordinates were from a stereotaxic atlas (32). An $\mathrm{Ag} / \mathrm{AgCl}$ reference electrode was implanted contralateral to the guide cannula in the left forebrain. A bipolar stimulating electrode was implanted in the $\mathrm{VTA} /$ substantia nigra (VTA/SN) (AP $-5.2 \mathrm{~mm}, \mathrm{ML}+1.2 \mathrm{~mm}$, dorsoventral (DV) -8.0 to $-9.0 \mathrm{~mm})$. Stimulation at these coordinates also activates the ventral noradrenergic bundle (VNB) (26). Stainless steel skull screws and dental cement secured all items.

\section{Intracranial Self-Stimulation (ICSS) Training}

After each animal recovered to their presurgery weight, ICSS training commenced as previously described (16). During recording sessions, an audiovisual cue was followed $2 \mathrm{~s}$ later by lever extension. Depression of the lever by the rat delivered an electrical stimulation to the animal. See Methods and Materials in Supplement 1 for more detail.

On the day of recording, some animals also underwent ICSS extinction where the leverpress did not deliver the electrical stimulation. When the cue no longer elicited lever-press behavior, ICSS was reinstated with 1-2 operator-delivered stimulations.

\section{Fast-scan Cyclic Voltammetry}

Following successful training, a fresh, glass-sealed carbon-fiber microelectrode (75-100 $\mu \mathrm{m}$ exposed tip length, $7 \mathrm{~m}$ diameter, T-650; Amoco, Greenville, SC $(33 ; 34))$ was lowered into the brain with a micromanipulator inserted into the guide cannula. The microelectrode was lowered to the dIBNST (DV -6.0 to $-7.0 \mathrm{~mm}$ ), the ${ }^{2}$ BNST (DV -7.2 to $-7.7 \mathrm{~mm}$ ) or the NAc shell (DV -6.4 to $-7.4 \mathrm{~mm}$ (16)). The carbon-fiber and $\mathrm{Ag} / \mathrm{AgCl}$ reference electrodes were connected to a head-mounted amplifier attached to a commutator (Med-Associates, St. Albans, VT). Fast-scan cyclic voltammetry was computer-controlled (35). A triangular scan $(-0.4$ to $+1.3 \mathrm{~V}, 400 \mathrm{~V} / \mathrm{s})$ was repeated every $100 \mathrm{~ms}$. Data were digitized and stored on a computer using software written in LABVIEW (National Instruments).

\section{Histology}

At the end of the experiment, electrode placements were verified by electrolytic lesions made with the carbon-fiber microelectrodes (Fig. S1 in Supplement 1) (26). Rats were euthanized with an overdose of urethane $(2.0 \mathrm{~g} / \mathrm{kg})$ and a lesion was made at the recording site by applying constant current ( $20 \mu \mathrm{A}$ for $10 \mathrm{~s})$. Brains were removed and stored in $10 \%$ formalin solution for a week before being sectioned into $40 \mu \mathrm{m}$ coronal slices. The sections were mounted on slides and viewed with an optical microscope.

\section{Chemicals and Drugs}

Chemicals and drugs were reagent-quality and used without further purification. Drugs were obtained from Sigma-Aldrich (St. Louis, MO, USA). Calibration of the carbon-fiber microelectrodes with standards for $\mathrm{pH}$, dopamine, and norepinephrine were made in a buffer (pH 7.4 containing $15 \mathrm{mM}$ Tris, $140 \mathrm{mM} \mathrm{NaCl}, 3.25 \mathrm{mM} \mathrm{KCl}, 1.2 \mathrm{mM} \mathrm{CaCl}_{2}, 1.25 \mathrm{mM}$ $\mathrm{NaH}_{2} \mathrm{PO}_{4}, 1.2 \mathrm{mM} \mathrm{MgCl}_{2}$, and $\left.2.0 \mathrm{mM} \mathrm{Na}_{2} \mathrm{SO}_{4}\right)$.

At least one pharmacological agent selective for each catecholamine was administered intraperitoneally (i.p.) at the end of every experiment $(0.6 \mathrm{~mL}$ volume) to verify the identity of the electrochemical signal (26). Cyclic voltammetry cannot be used to distinguish 
dopamine from norepinephrine and thus the pharmacological distinction is required (36).

Desipramine-HCl (DMI, $15 \mathrm{mg} / \mathrm{kg}$ ), raclopride- $\mathrm{HCl}$ ( $2 \mathrm{mg} / \mathrm{kg}$ ), and idazoxan-HCl (IDA, 5 $\mathrm{mg} / \mathrm{kg}$ ) were dissolved in saline. GBR 12909 (GBR, $15 \mathrm{mg} / \mathrm{kg}$ ) was dissolved in water and diluted in saline. For sites reported in the dIBNST positive responses were obtained to dopaminergic drugs (GBR, raclopride) but not noradrenergic drugs (DMI, IDA) whereas the opposite was true in the VBNST (Fig. S2 in Supplement 1) as described in a previous study (23). The limited chemical selectivity of cyclic voltammetry precludes its use in brain regions that employ both catecholamines as neurotransmitters.

\section{Data Analysis}

Catecholamine concentration changes were quantified using principal component regression $(37 ; 38)$. The post-calibration factors were from the average responses obtained with multiple electrodes in our previous studies $(23 ; 39)\left(6.9 \pm 0.3 \mathrm{pA} /\left(\mu \mathrm{M} \cdot \mu \mathrm{m}^{2}\right)\right.$ for dopamine, and $4.5 \pm 0.2 \mathrm{pA} /\left(\mu \mathrm{M} \cdot \mu \mathrm{m}^{2}\right)$ for norepinephrine $)$. A residual analysis procedure was used to verify that the cyclic voltammograms of the trials being predicted were consistent with the cyclic voltammograms used for calibration (40).

Clampfit 8.1 (Axon Instruments, Foster City, CA, USA) was used to analyze maximal catecholamine concentration evoked by the cue or lever-press. The half-life $\left(\mathrm{t}_{1 / 2}\right)$ for catecholamine clearance was taken as the time to descend from its maximum to half of that value (41). Only catecholamine concentrations with signal to noise $(\mathrm{S} / \mathrm{N})>3$ were considered as cue- or lever-press evoked catecholamine release. Concentration changes were evaluated by subtracting the average baseline ( -2.0 to $0 \mathrm{~s}$ relative to cue or lever-press) from events after the cue (0.1-2.0 s) or lever-press (2-15 s). Mean values were compared with the two-tailed Student's $t$-test to calculate the level of significance. The coefficient of variation $(\mathrm{CV}$, the ratio of the standard deviation of the mean) was used to characterize the catecholamine maximum concentrations. Statistical analysis employed GraphPad Software version 4.0 (San Diego, CA, USA). Data are represented as mean \pm S.E.M. and ' $n$ ' values indicate the number of rats.

\section{Results}

\section{Cue-evoked Dopamine Concentration Changes in the dIBNST during ICSS}

Following ICSS training, catecholamine release was measured in the dBNST. During training, the animal learned that a tone and house light were followed $2 \mathrm{~s}$ later by lever extension, and that a lever-press delivered ICSS stimulation to its brain (timing diagram in Fig. 1A). As shown for a single trial (Fig. 1B), dopamine release occurs both following the cues and the lever-press. The color plot shows the cyclic voltammograms recorded with the applied voltage as the ordinate and the abscissa as the acquisition time of the cyclic voltammogram. The current is encoded in color. The trace above the color plot is the dopamine concentration extracted from these data by principal component regression. The low residual confirms that the training set used to extract the dopamine concentrations describes the data appropriately (Fig. 1C).

Animals were allowed multiple ICSS trials. As shown in this animal, the cue-evoked maximal dopamine concentration $\left([\mathrm{DA}]_{\text {cue }}\right)$ was similar with each trial $\left([\mathrm{DA}]_{\text {cue }}=36.7 \pm\right.$ $2.6 \mathrm{nM}$ from the first 30 trials and $30.9 \pm 1.8 \mathrm{nM}$ from the last 30 trials, $\mathrm{t}_{29}=1.87, P>0.05$, Fig. 1D). In contrast, lever-press-evoked dopamine ([DA $]_{\text {stim. }}$ ) decreased significantly over trials and fit to a parabolic curve $\left(r^{2}=0.81\right.$, $[\mathrm{DA}]_{\mathrm{stim}}=278 \pm 11 \mathrm{nM}$ from the first 30 trials and $182 \pm 3 \mathrm{nM}$ from the last 30 trials, $\mathrm{t}_{29}=9.87, P<0.0001$, Fig. 1D). In both respects, the responses of dopamine were similar to our findings in the NAc (16). The latency to press after lever extension was essentially constant indicating that the animal had learned the 
behavior (Fig. 1E). Similar results were obtained in the d/BNST in 6 animals undergoing identical ICSS training. The average value of $[\mathrm{DA}]_{\text {cue }}$ was $27.8 \pm 5.3 \mathrm{nM}$ and for $[\mathrm{DA}]_{\text {stim. }}$. was $216 \pm 51 \mathrm{nM}$.

\section{Pharmacological Effects on Dopamine in the dIBNST}

For some animals, dopamine release during ICSS was also monitored following administration of inhibitors of dopamine uptake (GBR 12909) and norepinephrine uptake (DMI) $(\mathrm{n}=5$ animals). When examined 20 minutes after GBR $(\mathrm{n}=2)$, both cue- and leverpress-evoked dopamine concentrations significantly increased ([DA $]_{\text {cue }}=34.8 \pm 1.1 \mathrm{nM}$ before and $63.3 \pm 2.0 \mathrm{nM}$ after GBR, $\mathrm{t}_{49}=8.85, P<0.0001$; [DA $]_{\text {stim. }}=118 \pm 7 \mathrm{nM}$ before and $427 \pm 6 \mathrm{nM}$ after GBR, $\mathrm{t}_{49}=78.05, P<0.0001$, Fig. 2 , data recorded when both responses had stabilized in amplitude). Interestingly, the maximal cue evoked dopamine shows greater relative variation than do the stimulus-evoked changes. The CV was found to be 0.281 for cue-evoked dopamine release and 0.109 during electrically-stimulated dopamine release. The latency to lever-press decreased (but not significantly) after administration of GBR (predrug $=0.64 \pm 0.07 \mathrm{~s}$, after GBR $=0.47 \pm 0.05 \mathrm{~s}, \mathrm{t}_{49}=1.98, P>$ $0.05)$.

In contrast, DMI $(\mathrm{n}=3)$ did not significantly change cue-evoked dopamine concentration in the $d$ IBNST $\left([\mathrm{DA}]_{\text {cue }}=45.1 \pm 2.5 \mathrm{nM}\right.$ before and $41.6 \pm 2.0$ after DMI, $\mathrm{t}_{49}=0.98, P>0.05$, representative example in Fig. 3A). There was also no significant change in stimulated dopamine release $\left([\mathrm{DA}]_{\mathrm{stim}}=299 \pm 4 \mathrm{nM}\right.$ predrug and $[\mathrm{DA}]_{\mathrm{stim}} .=303 \pm 8 \mathrm{nM}$ after DMI, $\mathrm{t}_{49}=0.583, P>0.05$, Fig. 3B). DMI did significantly increase the latency to lever-press $\left(0.47 \pm 0.05 \mathrm{~s}\right.$ before and $0.76 \pm 0.06 \mathrm{~s}$ after DMI, $\left.\mathrm{t}_{49}=3.736, P<0.001\right)$. Following DMI, this animal was administered GBR. As with GBR alone, cue and lever-press-evoked dopamine concentrations were increased $\left([\mathrm{DA}]_{\mathrm{cue}}=99.4 \pm 4.8 \mathrm{nM}, \mathrm{t}_{49}=10.52, P<0.0001\right.$ and $\left.[\mathrm{DA}]_{\text {stim. }}=1226 \pm 64 \mathrm{nM}, \mathrm{t}_{49}=14.55, P<0.0001\right)$ and the latency to lever-press was restored to its original value $(0.49 \pm 0.06 \mathrm{~s})$.

\section{Norepinephrine Responses during Maintenance-delay Trials}

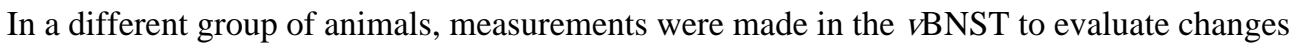
in extracellular norepinephrine concentration during an identical ICSS task. There was no response to the cue but norepinephrine increased during the electrical stimulation (Fig. 4A) that followed the lever-press. The residual (Fig. 4B) was below that predicted for $95 \%$ of the noise from the training set. In this animal, maximum lever-press-evoked norepinephrine concentration $\left([\mathrm{NE}]_{\text {stim. }}\right.$ ) decreased with subsequent trials $\left([\mathrm{NE}]_{\mathrm{stim} .}=288 \pm 8 \mathrm{nM}\right.$ from the first 30 trials and $213 \pm 4 \mathrm{nM}$ from the last 30 trials, $\mathrm{t}_{29}=8.160, P<0.0001$, Fig. 4 C), although the latency to lever-press did not significantly change with trials (Fig. 4D). Similar results were obtained in 6 other animals. The average value across all trials of $[\mathrm{NE}]_{\text {stim }}$ was $135 \pm 25 \mathrm{nM}$. The average latency to lever-press from these animals over 100 trials was 1.25 $\pm 0.27 \mathrm{~s}$. Norepinephrine release in response to the cue was never observed, even with extended training (Fig. S3 in Supplement 1).

\section{Pharmacological Effects on Norepinephrine in the vBNST}

In some animals norepinephrine changes during ICSS were evaluated after uptake inhibitors $(\mathrm{n}=3$ for GBR and $\mathrm{n}=4$ for DMI, example in Figure 5). DMI significantly increased stimulated release following the lever-press (from $[\mathrm{NE}]_{\text {stim }}=213 \pm 3 \mathrm{nM}$ to $[\mathrm{NE}]_{\text {stim }}=269$ $\pm 8 \mathrm{nM}$ after DMI, $\mathrm{t}_{49}=6.57, \mathrm{P}<0.0001,50$ trials) and the evoked signal gradually declined to predrug levels (Fig. 5A and B). Even following DMI, cue-evoked norepinephrine did not occur. The latency to lever-press following DMI increased significantly (latency was $0.97 \pm$ $0.16 \mathrm{~s}$ before drug and $1.96 \pm 0.42 \mathrm{~s}$ after drug, $\mathrm{t}_{49}=2.609, P<0.05$, Fig. $5 \mathrm{C}$ ). In a single animal that was administered GBR following DMI, the latency to lever-press was restored to 
its original value $(0.85 \pm 0.02 \mathrm{~s})$. Administration of GBR alone had a slight effect on the norepinephrine responses to stimulation $\left([\mathrm{NE}]_{\mathrm{stim}}=105 \pm 3 \mathrm{nM}\right.$ predrug and $[\mathrm{NE}]_{\mathrm{stim}}=99$ $\pm 2 \mathrm{nM}$ after GBR, $\mathrm{t}_{37}=2.044, \mathrm{P}<0.05$, Fig. $6 \mathrm{~A}$ and $\mathrm{B}$ ), however it did shorten the latency to lever-press $\left(1.74 \pm 0.26 \mathrm{~s}\right.$ before and $0.86 \pm 0.19 \mathrm{~s}$ after $\mathrm{GBR}, \mathrm{t}_{37}=2.801, \mathrm{P}<0.01$, Fig $6 \mathrm{C})$.

\section{Extracellular Changes of Dopamine and Norepinephrine during Extinction of ICSS}

During extinction, the sequence of cues and lever extension was unchanged; however, depression of the lever had no consequence. Previous studies have demonstrated that cueevoked dopamine release in the NAc decreased across extinction trials and this was accompanied by a decline in goal-directed behavior (16). In addition we found that dopamine in the NAc decreased during extinction at the time where the stimulation should have occurred by $18.3 \pm 1.4 \mathrm{nM}(\mathrm{n}=5$, individual example in Figure 7A, lever press indicated by dashed red line). Identical behavior was observed in the $d$ BBNST in one animal (Figure 7B). However, due to the low success rate of $d$ BBNST experiments, we primarily compare the behavior of norepinephrine in the $\mathrm{BBNST}$ with that of dopamine in the NAc shell (implantation success was approximately $17 \%$ in the $d$ BNST versus $80 \%$ in the NAc).

During extinction, norepinephrine was still unresponsive to the cue but it increased following the unrewarded lever-presses (example after the lever-press in one animal is shown in Fig. 7C). Data that was averaged and analyzed by principal component regression reveal an increase in norepinephrine concentration $(\mathrm{n}=5$ rats, $32.3 \pm 3.5 \mathrm{nM})$ following the lever-press during extinction trials. In two animals, norepinephrine changes during extinction were examined after administration of DMI. The norepinephrine response to extinction following the lever-press was significantly enhanced (from $38.0 \pm 3.6$ to $85.6 \pm$ $13.1 \mathrm{nM}$ following DMI, $\mathrm{t}_{5}=4.01, P<0.01$, example in Fig. S4 in Supplement 1), but there was still no change to the cue. Electrically evoked norepinephrine and ICSS behavior were restored during subsequent reinstatement trials.

\section{Discussion}

Here we found that dopamine release in the dIBNST in response to cues that predict lever availability closely resembles dopamine changes in the NAc (16; 42). In contrast, norepinephrine in the $\mathrm{r}$ BNST does not respond to the cue, even after prolonged training. However, both catecholamines are released after the lever-press as a consequence of the VNB and VTA/SN electrical stimulation. During ICSS extinction, cue-evoked dopamine disappears in the dIBNST just as in the NAc shell (16). As shown here, extracellular dopamine actually decreases at the time of the lever-press when electrical stimulation is expected but not delivered. Remarkably, during extinction, norepinephrine increases at the expected time of electrical stimulation. The opposite responses of these two catecholamines in the extended amygdala are in accord with a proposed role of this system in distinct aspects of the addiction cycle that includes both positive and negative reinforcement mechanisms $(43 ; 44)$. Dopamine relays information concerning positive hedonic states whereas the negative hedonic responses are mediated by norepinephrine (23).

\section{Different Roles for Each Catecholamine in Subregions of the BNST during ICSS}

Since the BNST is involved in the regulation of stress, homeostasis, and reward $(25 ; 30$; 45-48), activated catecholamine neurotransmission in this region during ICSS was anticipated. Indeed, previous experiments have demonstrated that dopamine neurotransmission is promoted in the dBNST during reward-based behaviors (49; 50), including ICSS (51). The temporal resolution provided by fast-scan cyclic voltammetry 
allowed us to distinguish catecholamine changes associated with the cues from those associated with the electrical stimulation. In the dIBNST dopamine was found to increase both in response to the cues that predict lever availability and during the self-administered (electrical) stimulation. The cue-evoked responses are similar to those observed in other dopaminergic regions during reward-based operant behaviors (18; 52-54). The greater variability of cue-induced dopamine transients when compared to stimulated release has been reported before (16). While the stimulation activates a uniform population of terminals on each trial, cue-induced dopamine appears to arise from a more variable activation of terminals.

This is the first time rapid recordings have been applied to norepinephrine during ICSS, and it has allowed us to reinvestigate the decades-old question of the role of norepinephrine in ICSS and extinction. Early studies suggested that the norepinephrine release was associated with reward function $(5 ; 6)$. Although our work confirms that norepinephrine release is evoked by a site that supports ICSS, it is not evoked by the predictive cue. Thus it clearly plays a different role than dopamine during ICSS.

When an animal acquires cue-reward associations, burst firing of midbrain dopaminergic neurons occurs at the onset of the cue $(20 ; 21)$. Previously, we have shown that time-locked dopamine concentration transients also occur in terminal regions at such times $(16 ; 55)$. Thus, dopamine release at the cue is one of the neurochemical responses that immediately elicits a goal-directed behavior $(4 ; 56)$. In contrast, cue-evoked norepinephrine was not observed in the VBNST. This is unlikely to be a consequence of norepinephrine transmission restricted to a synaptic compartment because considerable evidence indicates that it communicates extrasynaptically in the BNST $(31 ; 57)$. Indeed, electrophysiological studies have shown that noradrenergic neurons in the LC respond to novelty but lack a sustained response to stimuli $(58 ; 59)$.

To investigate whether selective uptake inhibitors affect ICSS, latency to press following DMI (NET inhibitor) or GBR 12909 (DAT inhibitor) was examined. In the absence of drug, the latency to lever-press was quite short because the animals were well trained. Overall, DMI significantly increased the latency to lever-press (Fig. 5C), consistent with the finding that acute DMI causes a decrement in ICSS reward (60). Following GBR administration, the latency to lever-press decreased but not significantly ( $P>0.05, n=5$ animals), presumably because of a ceiling effect. Supporting this assumption, in rats with an average latency to press of more than $1.0 \mathrm{~s}$ (example in Fig. 6) or who had previously received DMI, the latency was significantly decreased after GBR. Consistent with this finding, GBR has been shown to increase responding for ICSS reward (61).

\section{Opposing Catecholamine Changes during Extinction of ICSS}

Since identical dopamine responses were obtained during ICSS in the dIBNST as previously obtained in the NAc (16), we compared our previous dopamine results to those for norepinephrine in the $\mathrm{VBNST}$. During ICSS extinction, the decrease in lever-pressing was accompanied by a significant decrease in cue-evoked phasic dopamine in the NAc shell across trials (16), similar to that seen during extinction of cocaine self-administration (53). In addition, extracellular dopamine decreased at the time when the electrical stimulation should have occurred, consistent with electrophysiological data demonstrating reward prediction error $(62 ; 63)$.

A role for norepinephrine in the behavior observed during extinction of ICSS has long been suspected. During extinction of ICSS, animals with lesions of the locus coeruleus pressed the lever with more vigor and over a prolonged period compared to intact animals (64). This response was attributed to a failure of locus coeruleus-lesioned rats to pay attention to 
relevant cues. Subsequent research employing lesioned animals have provided support for this hypothesis (65), consistent with the view from electrophysiological studies in intact animals that norepinephrine neuronal systems are important in paying attention to the surrounding environment (66). Further, norepinephrine acting at central $\beta$-adrenergic receptors has been suggested to be important in the retrieval of drug-associated memories following extinction $(67 ; 68)$. Regardless, our data supports a role for norepinephrine during extinction. During ICSS, the $2 \mathrm{~s}$ cue predicts impending reward availability and results in a dopamine concentration transient without a change in norepinephrine. However, during extinction animals now learn that the $2 \mathrm{~s}$ cue predicts the absence of reward following a lever-press. This is associated with a norepinephrine surge. It is unlikely that this surge acts as a cue-associated signal since it occurs after the $2 \mathrm{~s}$ cue and any cues associated with the press itself (e.g., lever depression, click of the lever etc). A signal at the lever press is critical so that it can trigger a decline in goal-directed behavior; this requires new learning concerning the prediction of non-reward, a process that has been linked to norepinephrine $(69 ; 70)$.

Alternative hypotheses must also be considered. For example, the $v$ BNST receives noradrenergic input from the nucleus of the solitary tract as well as the locus coeruleus (71). These two nuclei have been shown to have quite different responses during aversive events such as opiate withdrawal (25), and, in the present experiments, we cannot distinguish which nuclei is the primary contributor to the measured norepinephrine release. In addition to its role in attention, norepinephrine release has also been associated with aversive stimuli. Using the same measurement approach, we previously showed that norepinephrine release was evoked by intraoral quinine infusion, an aversive tastant (23). Because the omission of reward can be considered aversive, this may also be the origin of the norepinephrine surge during ICSS extinction. In the prefrontal cortex, extracellular norepinephrine increases following both aversive and rewarding stimuli (72). However, those changes last for longer than an hour and it is unclear whether the rapid changes we report here have a similar origin.

\section{Conclusion}

Subsecond recordings of catecholamines in subregions of the BNST during ICSS reveal that time-locked catecholamine changes occur during this reward-seeking behavior. In a manner quite similar to events in the NAc shell, phasic dopamine release in the dIBNST was evoked by a cue that had become associated with ICSS. In contrast, there was no evidence of cueevoked, phasic norepinephrine in the ${ }_{\mathrm{BNNST}}$ during ICSS. Both catecholamines were released by the stimulation as a consequence of the positioning of the stimulating electrode in the VTA/SN/VNB. During extinction, the activity of both catecholamines was dramatically altered. Dopamine release to the cue diminished during ICSS extinction and the dopamine concentration actually decreased following the lever-press. At this time, when the cue no longer predicts impending ICSS availability and there is new learning about the consequence of the lever-press, extracellular norepinephrine increased. These data support the hypothesis that norepinephrine plays a central role in responses to extinction. Furthermore, the data demonstrate that catecholamine neurons in subregions of the BNST encode opposite aspects of learning during goal-directed behavior.

\section{Supplementary Material}

Refer to Web version on PubMed Central for supplementary material. 


\section{Acknowledgments}

This research was supported by NIH (NS 15841 to RMW, DA 010900 to RMW and RMC, and DA17318 to RMC and RMW).

\section{References}

1. Olds J, Milner P. Positive reinforcement produced by electrical stimulation of septal area and other regions of rat brain. Journal of comparative and physiological psychology. 1954; 47:419-427. [PubMed: 13233369]

2. Wise RA. Brain reward circuitry: insights from unsensed incentives. Neuron. 2002; 36:229-240. [PubMed: 12383779]

3. Wise RA. Addictive drugs and brain stimulation reward. Annual review of neuroscience. 1996; 19:319-340.

4. Weinshenker D, Schroeder JP. There and back again: a tale of norepinephrine and drug addiction. Neuropsychopharmacology. 2007; 32:1433-1451. [PubMed: 17164822]

5. Ritter S, Stein L. Self-stimulation in the mesencephalic trajectory of the ventral noradrenergic bundle. Brain Res. 1974; 81:145-157. [PubMed: 4611589]

6. Stein L, Wise CD. Release of norepinephrine from hypothalamus and amygdala by rewarding medial forebrain bundle stimulation and amphetamine. Journal of comparative and physiological psychology. 1969; 67:189-198. [PubMed: 4306672]

7. Clavier RM, Fibiger HC, Phillips AG. Evidence that self-stimulation of the region of the locus coeruleus in rats does not depend upon noradrenergic projections to telencephalon. Brain res. 1976; 113:71-81. [PubMed: 953735]

8. Corbett D, Skelton RW, Wise RA. Dorsal noradrenergic bundle lesions fail to disrupt selfstimulation from the region of locus coeruleus. Brain res. 1977; 133:37-44. [PubMed: 902089]

9. Corbett D, Wise RA. Intracranial self-stimulation in relation to the ascending noradrenergic fiber systems of the pontine tegmentum and caudal midbrain: a moveable electrode mapping study. Brain res. 1979; 177:423-436. [PubMed: 497844]

10. Roll SK. Intracranial self-stimulation and wakefulness: effect of manipulating ambient brain catecholamines. Science. 1970; 168:1370-1372. [PubMed: 4315436]

11. Fibiger HC. Drugs and reinforcement mechanisms: a critical review of the catecholamine theory. Annu Rev Pharmacol Toxicol. 1978; 18:37-56. [PubMed: 348064]

12. Lucki I, Frazer A. Performance and extinction of lever press behavior following chronic administration of desipramine to rats. Psychopharmacology (Berl). 1985; 85:253-259. [PubMed: 3923511]

13. Tombaugh TN, Pappas BA, Roberts DC, Vickers GJ, Szostak C. Failure to replicate the dorsal bundle extinction effect: telencephalic norepinephrine depletion does not reliably increase resistance to extinction but does augment gustatory neophobia. Brain Res. 1983; 261:231-242. [PubMed: 6403201]

14. Mason ST. Noradrenaline: reward or extinction ? Neurosci Biobehav Rev. 1979; 3:1-10.

15. Hernandez G, Shizgal P. Dynamic changes in dopamine tone during self-stimulation of the ventral tegmental area in rats. Behav Brain Res. 2009; 198:91-97. [PubMed: 18996152]

16. Owesson-White CA, Cheer JF, Beyene M, Carelli RM, Wightman RM. Dynamic changes in accumbens dopamine correlate with learning during intracranial self-stimulation. Proc Natl Acad Sci U S A. 2008; 105:11957-11962. [PubMed: 18689678]

17. Phillips PE, Stuber GD, Heien ML, Wightman RM, Carelli RM. Subsecond dopamine release promotes cocaine seeking. Nature. 2003; 422:614-618. [PubMed: 12687000]

18. Day JJ, Roitman MF, Wightman RM, Carelli RM. Associative learning mediates dynamic shifts in dopamine signaling in the nucleus accumbens. Nat Neurosci. 2007; 10:1020-1028. [PubMed: 17603481]

19. Sombers LA, Beyene M, Carelli RM, Wightman RM. Synaptic overflow of dopamine in the nucleus accumbens arises from neuronal activity in the ventral tegmental area. J Neurosci. 2009; 29:1735-1742. [PubMed: 19211880] 
20. Schultz W, Dayan P, Montague PR. A neural substrate of prediction and reward. Science. 1997; 275:1593-1599. [PubMed: 9054347]

21. Pan WX, Schmidt R, Wickens JR, Hyland BI. Dopamine cells respond to predicted events during classical conditioning: evidence for eligibility traces in the reward-learning network. J Neurosci. 2005; 25:6235-6242. [PubMed: 15987953]

22. Cullinan WE, Herman JP, Watson SJ. Ventral subicular interaction with the hypothalamic paraventricular nucleus: evidence for a relay in the bed nucleus of the stria terminalis. J Comp Neurol. 1993; 332:1-20. [PubMed: 7685778]

23. Park J, Wheeler RA, Fontillas K, Keithley RB, Carelli RM, Wightman RM. Catecholamines in the bed nucleus of the stria terminalis reciprocally respond to reward and aversion. Biol Psychiatry. 2012; 71:327-334. [PubMed: 22115620]

24. Kilts CD, Anderson CM. The simultaneous quantification of dopamine, norepinephrine and epinephrine in micropunched rat brain nuclei by on-line trace enrichment HPLC with electrochemical detection: Distribution of catecholamines in the limbic system. Neurochem Int. 1986; 9:437-445. [PubMed: 20493144]

25. Delfs JM, Zhu Y, Druhan JP, Aston-Jones G. Noradrenaline in the ventral forebrain is critical for opiate withdrawal-induced aversion. Nature. 2000; 403:430-434. [PubMed: 10667795]

26. Park J, Kile BM, Wightman RM. In vivo voltammetric monitoring of norepinephrine release in the rat ventral bed nucleus of the stria terminalis and anteroventral thalamic nucleus. Eur J Neurosci. 2009; 30:2121-2133. [PubMed: 20128849]

27. Carboni E, Silvagni A, Rolando MT, Di Chiara G. Stimulation of in vivo dopamine transmission in the bed nucleus of stria terminalis by reinforcing drugs. J Neurosci. 2000; 20:RC102. [PubMed: 11027253]

28. Phelix CF, Liposits Z, Paull WK. Catecholamine-CRF synaptic interaction in a septal bed nucleus: afferents of neurons in the bed nucleus of the stria terminalis. Brain Res Bull. 1994; 33:109-119. [PubMed: 7903902]

29. Meloni EG, Gerety LP, Knoll AT, Cohen BM, Carlezon WA Jr. Behavioral and anatomical interactions between dopamine and corticotropin-releasing factor in the rat. J Neurosci. 2006; 26:3855-3863. [PubMed: 16597740]

30. McElligott ZA, Winder DG. Modulation of glutamatergic synaptic transmission in the bed nucleus of the stria terminalis. Prog Neuropsychopharmacol Biol Psychiatry. 2009; 33:1329-1335. [PubMed: 19524008]

31. Phelix CF, Liposits Z, Paull WK. Monoamine innervation of bed nucleus of stria terminalis: an electron microscopic investigation. Brain Res Bull. 1992; 28:949-965. [PubMed: 1379113]

32. Paxinos, G.; Watson, C. The Rat Brain in Stereotaxic Coordinates. 6th ed. Elsevier Inc; Burlington: 2007.

33. Cahill PS, Wightman RM. Simultaneous amperometric measurement of ascorbate and catecholamine secretion from individual bovine adrenal medullary cells. Anal Chem. 1995; 67:2599-2605. [PubMed: 8849026]

34. Phillips PE, Robinson DL, Stuber GD, Carelli RM, Wightman RM. Real-time measurements of phasic changes in extracellular dopamine concentration in freely moving rats by fast-scan cyclic voltammetry. Methods Mol Med. 2003; 79:443-464. [PubMed: 12506716]

35. Heien ML, Phillips PE, Stuber GD, Seipel AT, Wightman RM. Overoxidation of carbon-fiber microelectrodes enhances dopamine adsorption and increases sensitivity. Analyst. 2003; 128:1413-1419. [PubMed: 14737224]

36. Park J, Wheeler RA, Fontillas K, Keithley RB, Carelli RM, Wightman RM. Catecholamines in the Bed Nucleus of the Stria Terminalis Reciprocally Respond to Reward and Aversion. Biological psychiatry. 2011

37. Heien ML, Khan AS, Ariansen JL, Cheer JF, Phillips PE, Wassum KM, et al. Real-time measurement of dopamine fluctuations after cocaine in the brain of behaving rats. Proc Natl Acad Sci U S A. 2005; 102:10023-10028. [PubMed: 16006505]

38. Keithley RB, Carelli RM, Wightman RM. Rank estimation and the multivariate analysis of in vivo fast-scan cyclic voltammetric data. Anal Chem. 2010; 82:5541-5551. [PubMed: 20527815] 
39. Park J, Aragona BJ, Kile BM, Carelli RM, Wightman RM. In vivo voltammetric monitoring of catecholamine release in subterritories of the nucleus accumbens shell. Neuroscience. 2010; 169:132-142. [PubMed: 20451589]

40. Keithley RB, Heien ML, Wightman RM. Multivariate concentration determination using principal component regression with residual analysis. Trends Analyt Chem. 2009; 28:1127-1136.

41. Park J, Galligan JJ, Fink GD, Swain GM. Differences in sympathetic neuroeffector transmission to rat mesenteric arteries and veins as probed by in vitro continuous amperometry and video imaging. J Physiol. 2007; 584:819-834. [PubMed: 17761778]

42. Beyene M, Carelli RM, Wightman RM. Cue-evoked dopamine release in the nucleus accumbens shell tracks reinforcer magnitude during intracranial self-stimulation. Neuroscience. 2010; 169:1682-1688. [PubMed: 20600644]

43. Solomon RL, Corbit JD. An opponent-process theory of motivation. I. Temporal dynamics of affect. Psychol Rev. 1974; 81:119-145. [PubMed: 4817611]

44. Koob GF, Volkow ND. Neurocircuitry of addiction. Neuropsychopharmacology. 2010; 35:217238. [PubMed: 19710631]

45. Cecchi M, Khoshbouei H, Javors M, Morilak DA. Modulatory effects of norepinephrine in the lateral bed nucleus of the stria terminalis on behavioral and neuroendocrine responses to acute stress. Neuroscience. 2002; 112:13-21. [PubMed: 12044468]

46. Erb S, Hitchcott PK, Rajabi H, Mueller D, Shaham Y, Stewart J. Alpha-2 adrenergic receptor agonists block stress-induced reinstatement of cocaine seeking. Neuropsychopharmacology. 2000; 23:138-150. [PubMed: 10882840]

47. Sullivan GM, Apergis J, Bush DE, Johnson LR, Hou M, Ledoux JE. Lesions in the bed nucleus of the stria terminalis disrupt corticosterone and freezing responses elicited by a contextual but not by a specific cue-conditioned fear stimulus. Neuroscience. 2004; 128:7-14. [PubMed: 15450349]

48. Fendt M, Siegl S, Steiniger-Brach B. Noradrenaline transmission within the ventral bed nucleus of the stria terminalis is critical for fear behavior induced by trimethylthiazoline, a component of fox odor. J Neurosci. 2005; 25:5998-6004. [PubMed: 15976089]

49. Epping-Jordan MP, Markou A, Koob GF. The dopamine D-1 receptor antagonist SCH 23390 injected into the dorsolateral bed nucleus of the stria terminalis decreased cocaine reinforcement in the rat. Brain Res. 1998; 784:105-115. [PubMed: 9518570]

50. Eiler WJ 2nd, Seyoum R, Foster KL, Mailey C, June HL. D1 dopamine receptor regulates alcoholmotivated behaviors in the bed nucleus of the stria terminalis in alcohol-preferring $(\mathrm{P})$ rats. Synapse. 2003; 48:45-56. [PubMed: 12557272]

51. Jonkman S, Markou A. Blockade of nicotinic acetylcholine or dopamine D1-like receptors in the central nucleus of the amygdala or the bed nucleus of the stria terminalis does not precipitate nicotine withdrawal in nicotine-dependent rats. Neurosci Lett. 2006; 400:140-145. [PubMed: 16563623]

52. Day JJ, Jones JL, Wightman RM, Carelli RM. Phasic nucleus accumbens dopamine release encodes effort- and delay-related costs. Biological psychiatry. 2010; 68:306-309. [PubMed: 20452572]

53. Stuber GD, Wightman RM, Carelli RM. Extinction of cocaine self-administration reveals functionally and temporally distinct dopaminergic signals in the nucleus accumbens. Neuron. 2005; 46:661-669. [PubMed: 15944133]

54. Jones JL, Day JJ, Aragona BJ, Wheeler RA, Wightman RM, Carelli RM. Basolateral amygdala modulates terminal dopamine release in the nucleus accumbens and conditioned responding. Biological psychiatry. 2010; 67:737-744. [PubMed: 20044074]

55. Cheer JF, Aragona BJ, Heien ML, Seipel AT, Carelli RM, Wightman RM. Coordinated accumbal dopamine release and neural activity drive goal-directed behavior. Neuron. 2007; 54:237-244. [PubMed: 17442245]

56. Wise RA. Dopamine, learning and motivation. Nat Rev Neurosci. 2004; 5:483-494. [PubMed: 15152198]

57. Miles PR, Mundorf ML, Wightman RM. Release and uptake of catecholamines in the bed nucleus of the stria terminalis measured in the mouse brain slice. Synapse. 2002; 44:188-197. [PubMed: $11954051]$ 
58. Sara SJ, Vankov A, Herve A. Locus coeruleus-evoked responses in behaving rats: a clue to the role of noradrenaline in memory. Brain Res Bull. 1994; 35:457-465. [PubMed: 7859103]

59. Bouret S, Sara SJ. Reward expectation, orientation of attention and locus coeruleus-medial frontal cortex interplay during learning. Eur J Neurosci. 2004; 20:791-802. [PubMed: 15255989]

60. Hall FS, Stellar JR, Kelley AE. Acute and chronic desipramine treatment effects on rewarding electrical stimulation of the lateral hypothalamus. Pharmacol Biochem Behav. 1990; 37:277-281. [PubMed: 2080191]

61. Maldonado-Irizarry CS, Stellar JR, Kelley AE. Effects of cocaine and GBR-12909 on brain stimulation reward. Pharmacol Biochem Behav. 1994; 48:915-920. [PubMed: 7972296]

62. Mirenowicz J, Schultz W. Preferential activation of midbrain dopamine neurons by appetitive rather than aversive stimuli. Nature. 1996; 379:449-451. [PubMed: 8559249]

63. Ungless MA, Magill PJ, Bolam JP. Uniform inhibition of dopamine neurons in the ventral tegmental area by aversive stimuli. Science. 2004; 303:2040-2042. [PubMed: 15044807]

64. Mason ST, Iversen SD. Theories of the dorsal bundle extinction effect. Brain res. 1979; 180:107137. [PubMed: 385111]

65. Selden NR, Robbins TW, Everitt BJ. Enhanced behavioral conditioning to context and impaired behavioral and neuroendocrine responses to conditioned stimuli following ceruleocortical noradrenergic lesions: support for an attentional hypothesis of central noradrenergic function. $\mathrm{J}$ Neurosci. 1990; 10:531-539. [PubMed: 2303858]

66. Aston-Jones G, Cohen JD. An integrative theory of locus coeruleus-norepinephrine function: adaptive gain and optimal performance. Annual review of neuroscience. 2005; 28:403-450.

67. Fricks-Gleason AN, Marshall JF. Post-retrieval beta-adrenergic receptor blockade: effects on extinction and reconsolidation of cocaine-cue memories. Learning \& memory. 2008; 15:643-648. [PubMed: 18772251]

68. Otis JM, Mueller D. Inhibition of beta-adrenergic receptors induces a persistent deficit in retrieval of a cocaine-associated memory providing protection against reinstatement. Neuropsychopharmacology : official publication of the American College of Neuropsychopharmacology. 2011; 36:1912-1920. [PubMed: 21544069]

69. Mason ST. The neurochemistry and pharmacology of extinction behavior. Neurosci Biobehav Rev. 1983; 7:325-347. [PubMed: 6142438]

70. Janak PH, Corbit LH. Deepened extinction following compound stimulus presentation: noradrenergic modulation. Learning \& memory (Cold Spring Harbor, NY. 2011; 18:1-10.

71. Park J, Kile BM, Wightman RM. In vivo voltammetric monitoring of norepinephrine release in the rat ventral bed nucleus of the stria terminalis and anteroventral thalamic nucleus. Eur J Neurosci. 2009; 30:2121-2133. [PubMed: 20128849]

72. Ventura R, Morrone C, Puglisi-Allegra S. Prefrontal/accumbal catecholamine system determines motivational salience attribution to both reward- and aversion-related stimuli. Proceedings of the National Academy of Sciences of the United States of America. 2007; 104:5181-5186. [PubMed: 17360372] 


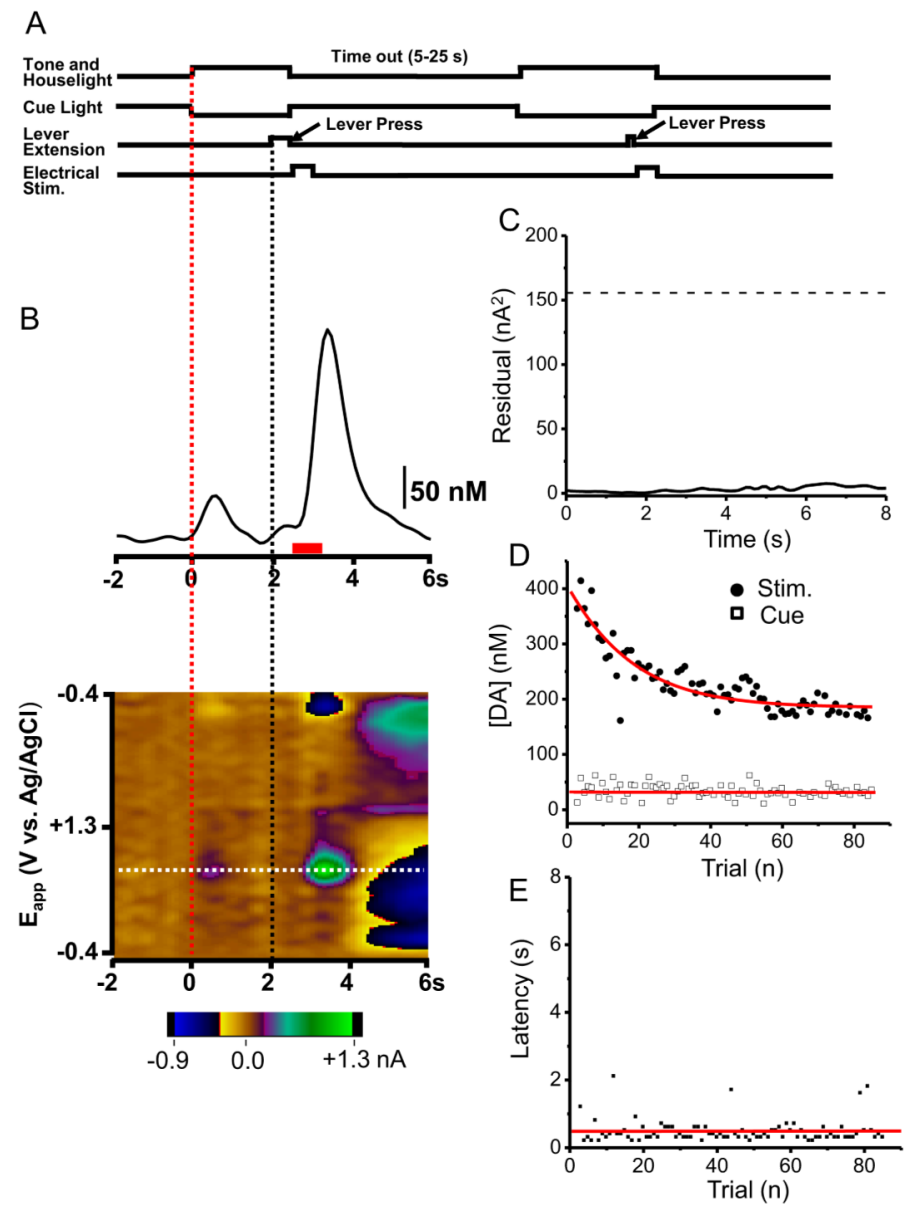

Figure 1.

Dopamine changes in the $d$ BNST during maintenance-delay ICSS. (A) Temporal sequence of task. (B) Upper; a representative temporal dopamine concentration trace from a single trial during maintenance-delay ICSS. Principal component regression was used to extract the time course of the dopamine concentration transients. Dopamine release occurs immediately following the cue $(\mathrm{t}=0$, red dotted line) and again after the lever-press (lever out at $2 \mathrm{~s}$, black dotted line). Red bar shows the stimulus duration. Lower: two-dimensional color plot representation of the background subtracted cyclic voltammograms collected $2 \mathrm{~s}$ before cue and $6 \mathrm{~s}$ after the lever extension. Catecholamine concentration changes are apparent in color plots at the potential for its oxidation $(\sim 0.65 \mathrm{~V}$, white dashed line) and its reduction $(\sim-0.2$ V). (C) Residual from principal component analysis. (D) Cue- and lever-press-evoked dopamine release across trials. (E) Latency to press the lever across trials. Stimulus parameters: $60 \mathrm{~Hz}, 40$ biphasic pulses, $2 \mathrm{~ms}$ pulse width. 


\section{Dopamine in $d / B N S T$}
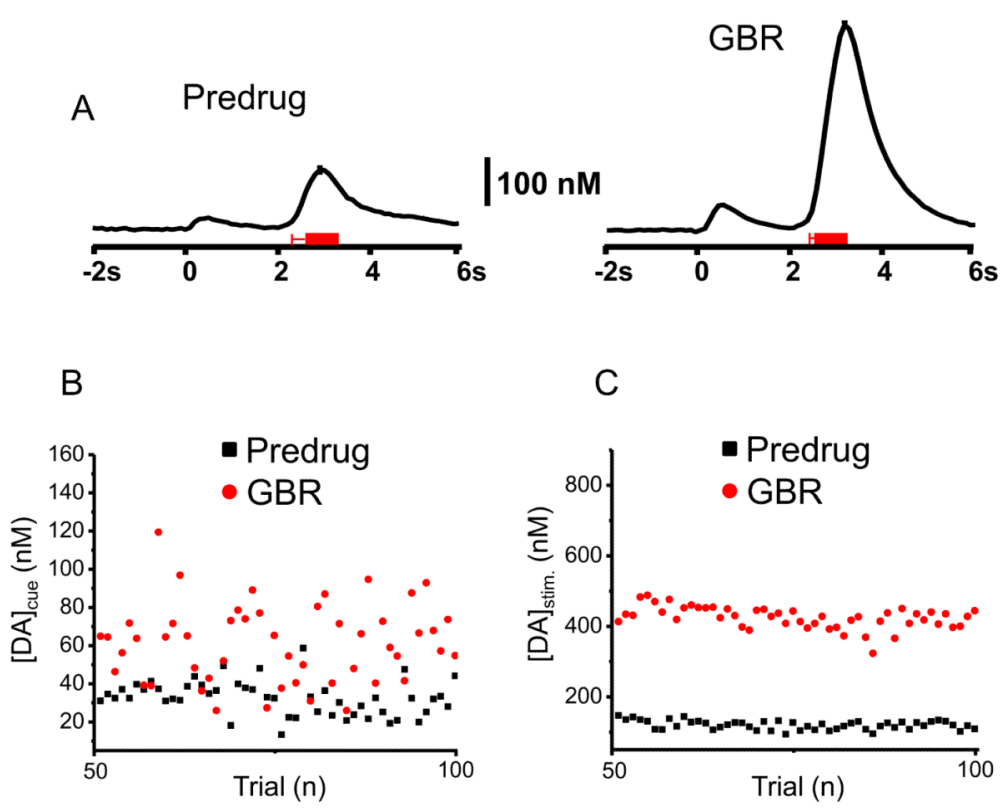

Figure 2.

Dopamine increase in the dBNST during maintenance-delay ICSS after administration of GBR. (A) Average dopamine concentration traces with a representative \pm S.E.M. and twodimensional color plots from 50 trials before drug session (predrug, left) and $20 \mathrm{~min}$ after the administration of GBR (15 mg/kg, i.p., right). Principal component regression was used to extract time course of the dopamine concentration traces. The red bars under the current traces denote the average onset and duration of electrical stimulation. (B) Cue- and (C) lever-press-evoked dopamine concentration changes across trials. 


\section{Dopamine in d/BNST}
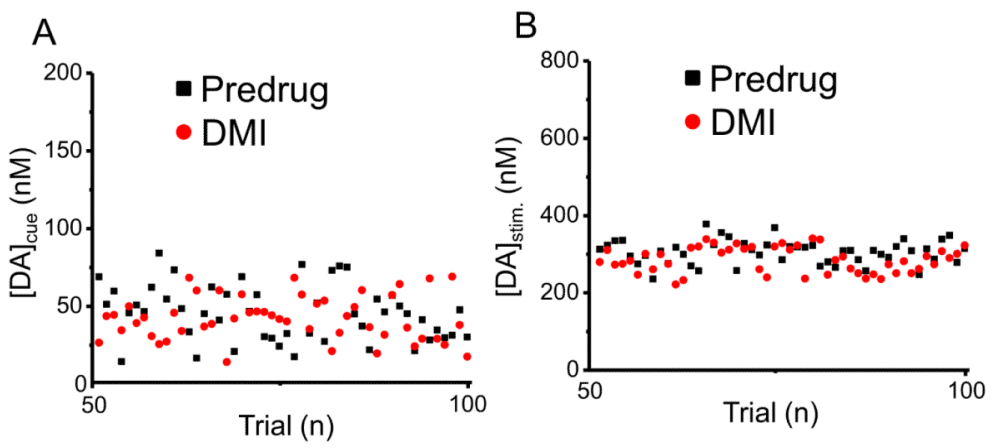

Figure 3.

Dopamine concentration changes in the $d / B N S T$ and latency to lever-press during maintenance-delay ICSS before and after administration of DMI. Responses are only shown for 50 trials after the initial decay in stimulated release had occurred. Maximum dopamine concentrations following (A) the cue and (B) the lever-press as a function of trial number. 


\section{A}

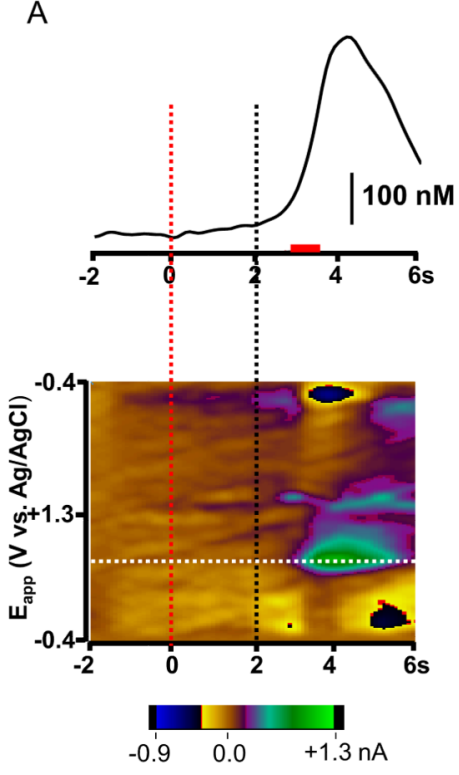

B

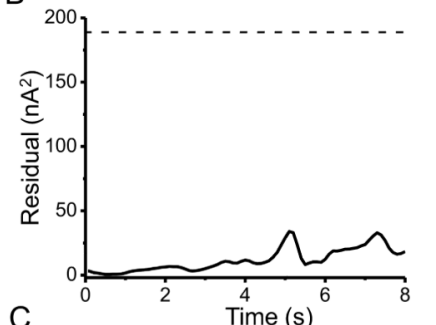

C
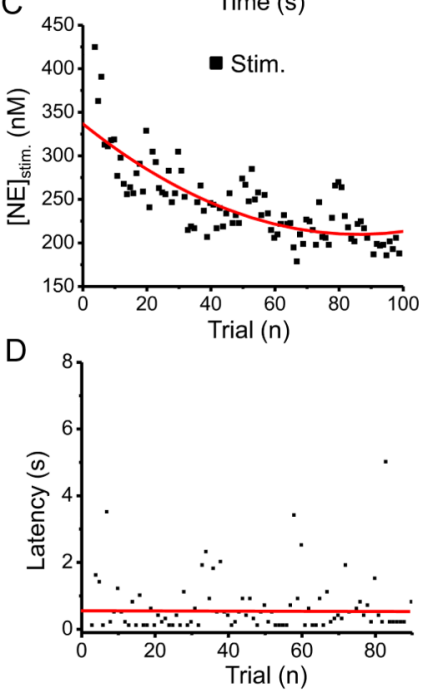

Figure 4.

Norepinephrine changes in the ${ }^{B}$ BNST during maintenance-delay ICSS. (A) Upper; a representative temporal norepinephrine concentration trace from a single trial during the task. Principal component regression was used to extract time course of the norepinephrine concentration transients. Norepinephrine was evoked after the lever-press (lever out at $2 \mathrm{~s}$, black dotted line) but not after the cue $(t=0$, red dotted line). Red bar shows the stimulus duration. Lower; Two-dimensional color plot representation of the background subtracted cyclic voltammograms collected $2 \mathrm{~s}$ before cue and $6 \mathrm{~s}$ after the lever extension.

Catecholamine concentration changes are apparent in color plots at the potential for its oxidation $(\sim 0.65 \mathrm{~V})$ and its reduction $(\sim-0.23 \mathrm{~V})$. (B) Residual from principal component regression. The dashed line shows the level where $95 \%$ of the noise is anticipated. (C) Norepinephrine concentration changes evoked by self-delivered stimulation in consecutive trials. (D) Latency to press the lever in consecutive trials. 

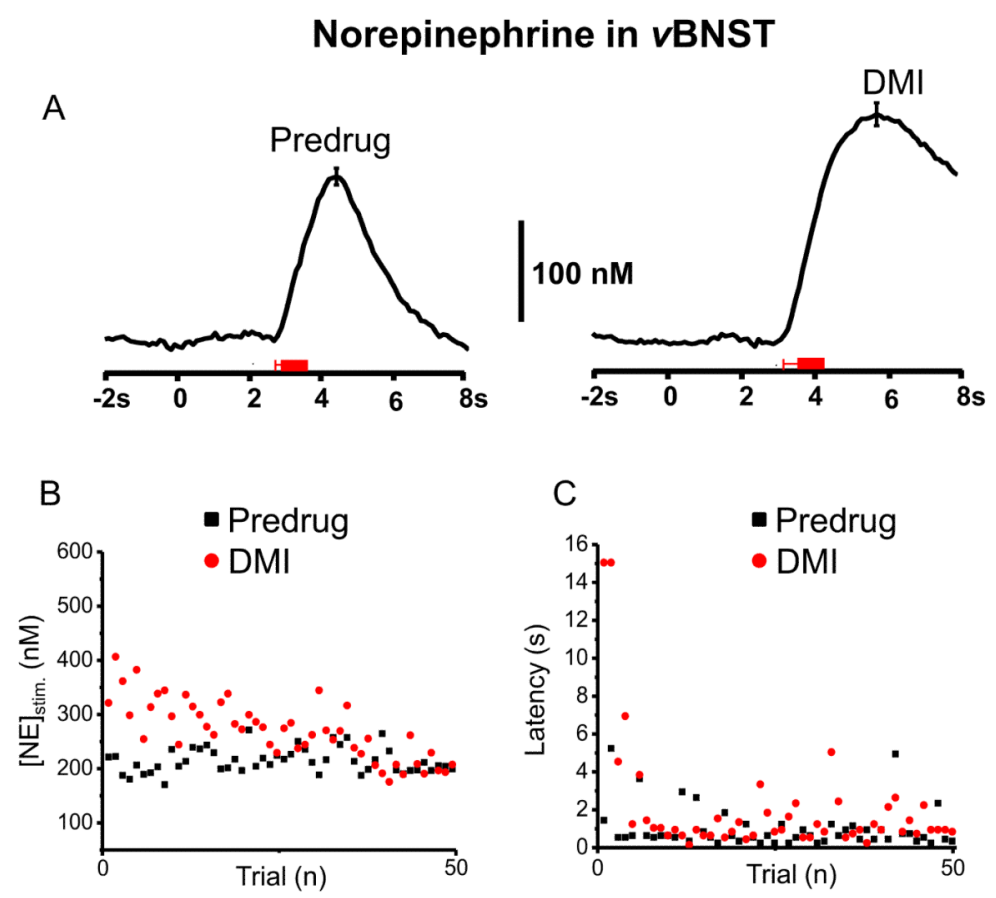

Figure 5.

Norepinephrine increase in the $v B N S T$ during maintenance-delay ICSS after administration of DMI. (A) Average norepinephrine concentration traces with a representative \pm S.E.M. from $~ 50$ trials before drug session (predrug, left) and $20 \mathrm{~min}$ after the administration of DMI (DMI, $15 \mathrm{mg} / \mathrm{kg}$, i.p., right). The red bars under the current traces denote the average onset and duration of electrical stimulation. Principal component regression was used to extract the time course of the norepinephrine concentration traces. (B) Lever-press-evoked norepinephrine concentration change and $(\mathrm{C})$ the latency of lever-press across trials. 


\section{Norepinephrine in vBNST}

A
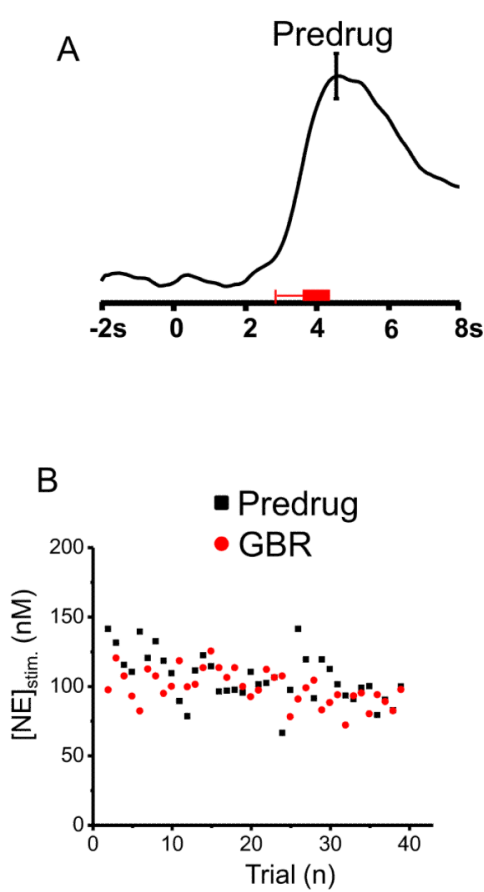
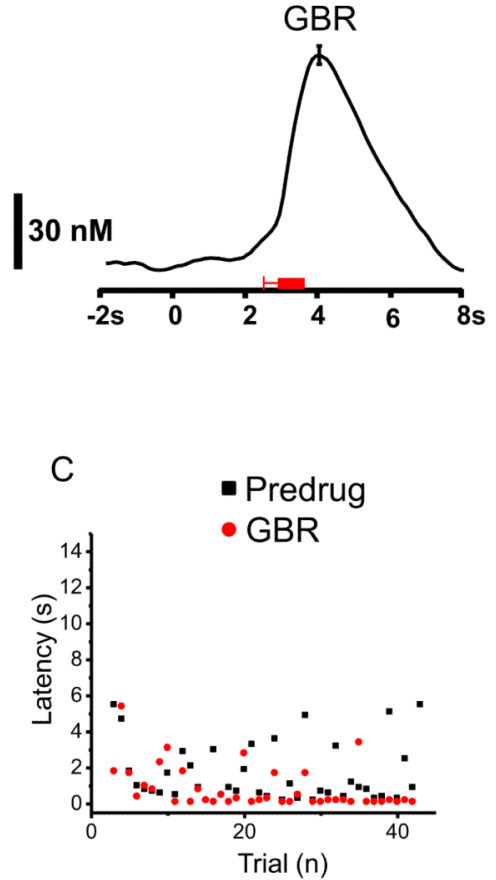

Figure 6.

Norepinephrine concentration change in the $v \mathrm{BNST}$ and latency of the lever-press during maintenance-delay ICSS after administration of GBR. (A) Average norepinephrine concentration traces with a representative \pm S.E.M. and from $\sim 50$ trials 20 min after the administration GBR (15 mg/kg, i.p.). The red bars under the current traces denote the average onset and duration of electrical stimulation. Principal component regression was used to extract time course of the norepinephrine concentration traces. (B) Lever pressevoked norepinephrine concentration change and (C) the latency of lever-press across trials. 


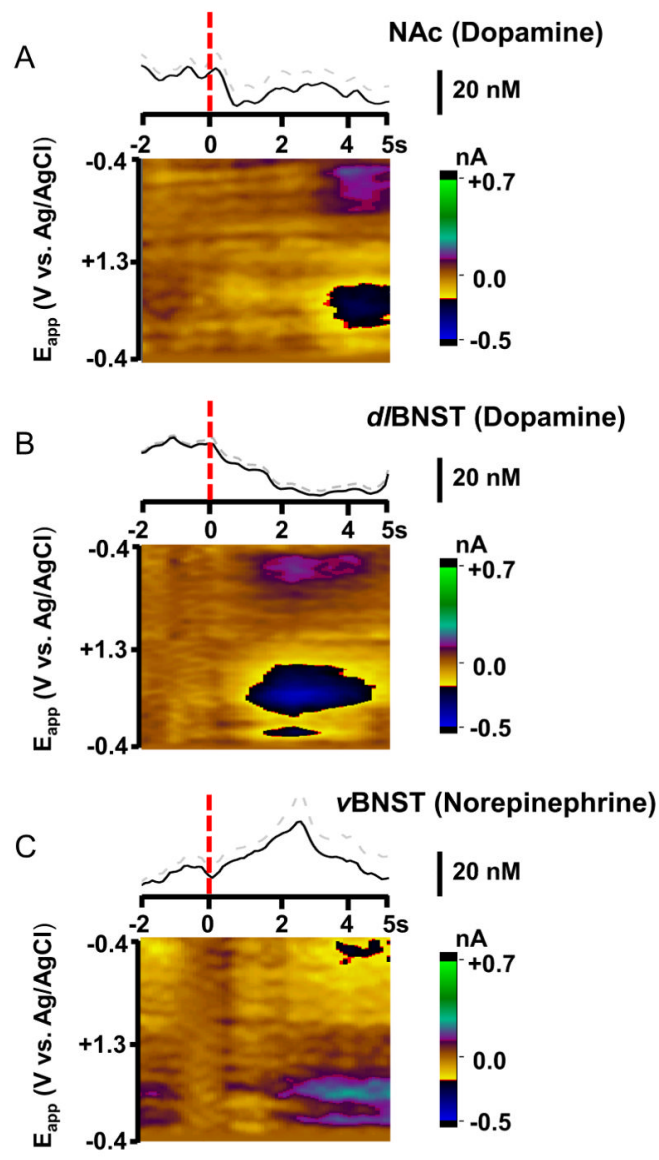

Figure 7.

Catecholamine responses in the NAc (A), dIBNST (B) and $v$ BNST (C) during ICSS extinction. Each data set is averaged from a single animal. The concentration profiles (displayed as mean and S.E.M.) above the 2D color plots were extracted using principal component analysis. Time of lever-press is indicated by the red dotted line. In extinction trials lever-press was not rewarded with electrical stimulation. 